\title{
Measuring hospital service quality and its influence on patient satisfaction: An empirical study using structural equation modeling
}

\author{
Nasim Kazemi*, Parisa Ehsani, Farshid Abdi and Mohammad Kazem Bighami
}

Industrial Engineering Department, South Tehran Branch, Islamic Azad University, Tehran, Iran

\section{H R O N I C L E A B S T R A C T}

Article history:

Received January 30, 2013

Received in revised format

20 May 2013

Accepted May 282013

Available online

June 32013

Keywords:

Hospital service quality

Patient satisfaction

structural equation modeling

(SEM)

\begin{abstract}
This paper presents an empirical investigation to measure different dimensions of hospital service quality (HSQ) by gap analysis and patient satisfaction (PS). It also attempts to measure patients' satisfaction with three dimensions extracted from exploratory factor analysis (EFA) by Principle component analysis method and conformity factor analysis (CFA). In addition, the study analyzes relationship between HSQ and PS in the context of Iranian hospital services, using structural equation modeling (SEM) from patients' perspectives. The maximum gap observed in "responsiveness" and the minimum one in "assurance". In addition, patients had the most satisfaction in "trust" with the mean of 3.83 followed by "General Satisfaction" with the mean of 3.68 and they had the least satisfaction in "Acceptance" with the mean of 3.53.

Two measurement models were used for measuring hospital service quality and patient satisfaction and one structural model, which showed the relationship between them. The result of this study showed that there was a positive and significant impact from hospital service quality on patient satisfaction (0.463). In addition, there was a positive and significant relationship between hospital service quality and five dimensions. Furthermore, it was shown that patient satisfaction and three dimensions (General Satisfaction, Trust, and Acceptance) were associated with each other, significantly and positively. At last management strategies and practical suggestions were presented to hospital.
\end{abstract}

\section{Introduction}

Health care is one of the fastest growing sectors in the service economy (Andaleeb, 2001). Healthcare delivery systems in developing countries call for an efficient management to increase the effectiveness of healthcare systems, Because the resources do not meet existing demands placed on services of healthcare institutions, and also the possibility of resources being increased in the short term is quite different (Padma et al., 2010). Hospitals in developing countries spend more resources than other kind of recurrent government on health. A review of health sectors in many countries 
indicated that because of the technical and managerial inefficiency within hospitals, large recurrent expenditures on hospitals involve a great waste of resources. (Tabish, 1998). Patient satisfaction and service quality are critical components in strategic planning processes; because as a result of increasing in better technology, patients are more informed than ever and if they are not satisfied, they will switch to an alternative health care provider (Ramsaran-Fowdar, 2008). A positive customer experience affects corporate business performance, including profitability, productivity, market share, and reduce costs (Zeithaml, 2000).

The objectives of the current study are: 1- Measuring the dimensions of hospital service quality (HSQ) by gap analysis and patient satisfaction (PS) 2- The extension of an instrument to measure the patient satisfaction with three dimensions extracted from exploratory factor analysis (EFA)by Principle component analysis method and conformity factor analysis (CFA) 3- Analyzing the relationship between HSQ and PS in the context of Iranian hospital services, using structural equation modeling (SEM) from the perspective of patients.

\section{Literature review}

\subsection{Service quality}

Service quality is defined as "a global judgment or attitude relating to the overall excellence or superiority of the service" (Parasuraman et al., 1988). Also, service quality is defined as a customer's overall service quality evaluation by applying a disconfirmation model - the gap between service expectations and performance (Cronin Jr \& Taylor, 1992; Potter et al., 1994). Perceptions of service quality enable providers of healthcare to detect services and processes in need of improvement. Providers perceive that satisfying patients can save them time and money spent on resolving patient complaints in future (Pakdil \& Harwood, 2005).

The SERVQUAL instrument is a popular instrument to measure service quality applied in the healthcare industry extensively. Five dimensions (i.e., assurance, empathy, reliability, responsiveness and tangibles) are proposed and the magnitude of the differences between customer perceptions and expectations are implemented for measuring perceived service quality (Parasuraman et al., 1988).

-Tangibles: The appearance of physical facilities, equipment, appearance of personnel, and communication materials.

- Reliability: The ability of hospital to perform the promised service dependably and accurately (i.e., when something is promised, it is done and provision of services at the time promised).

- Responsiveness: The willingness of hospital's personnel to help customers and provide prompt service.

- Assurance: The knowledge and courtesy of hospital employees and their ability to inspire trust and confidence.

- Empathy: The caring, individualized attention the hospital provides to its customers (i.e. employees understand specific needs and employees give personal attention).

\subsection{Patient satisfaction}

There are normally three reasons to measure patient satisfaction: (a) Patient satisfaction is the primary objective of the healthcare provider innately; (b) Patient satisfaction gives us useful data about the structure, process and outcome of healthcare, and (c) Satisfied and dissatisfied patients have various 
behavioral intentions. For instance, highly satisfied patients are more compliant with physician advice and to recommend the healthcare provider to their relatives and friends (Boudreaux \& O'Hea, 2004).

\subsection{Relationship between service quality and Patient satisfaction in healthcare industry}

There is a reverse relationship between service quality and customer satisfaction and they are divided into two categories: The first one says that satisfied customer leads to a good perceptions of service quality (Bolton \& Drew, 1991) and the second one recommends that service quality leads to customer satisfaction (Cronin Jr \& Taylor, 1992; Spreng \& Mackoy, 1996). These two categories confirm that there is a strong correlation between customer satisfaction and service quality. Andaleeb (2001) studied the relationship between customer satisfaction and service quality. The five-dimension framework of perceived service quality was described in Bangladesh hospitals as responsiveness, assurance, communication, discipline (tangible), and baksheesh (tips). All five dimensions of service quality were significant in explaining patient satisfaction. Discipline and then assurance had bigger impact on patient satisfaction than the others (Andaleeb, 2001).

Tucker and Adams (2001) argued that quality variables could include caring, empathy, reliability, and responsiveness. Satisfaction variables were Access, Communication, and outcomes. In their study, on patient satisfaction at American public hospitals, the performance of the service provider and access provider serving were established approximately $74 \%$ of the express consent variances (Tucker \& Adams, 2001). The result of Boshoff and Gray (2004) investigation demonstrated that the service quality dimensions, Empathy of nursing staff and Assurance, influence on Loyalty and Cumulative satisfaction, significantly. The customer satisfaction dimensions including Satisfaction with meals, Satisfaction with the nursing staff and Satisfaction with fees may also have some impact on Loyalty and cumulative satisfaction, substantially (Boshoff \& Gray, 2004).

Choi, Lee, Kim, Lee (2005) in South Korea hospitals explained that the relationship between service quality dimensions and patient satisfaction among patients based on age, gender and types of services received, did not differ (Choi et al., 2005). Padma et al. (2010) developed an instrument to measure service quality perceptions of patients and attendants. The eight dimensions of SQ for healthcare services include infrastructure, personnel quality, process of clinical care, administrative procedures, safety indicators, hospital image, social responsibility, and trustworthiness of the hospital. Moreover, the relationship between SQ and customer satisfaction (CS) in government and private hospitals in India were investigated by implementing regression from the perspectives of patients and their attendants. Personnel quality recognized as the most essential factor from the perspective of patients and their attendants (Padma et al., 2010). Owusa-Frimpong et al. (2010) measured service quality and patient satisfaction with access to treatment in public and private healthcare sectors in London. User of public and private healthcare maintained major problems in reaching healthcare and access to care problems was reported to be significant. Managers should pay special attention to it to improve the quality of service delivery and patient satisfaction (Owusu-Frimpong et al., 2010).

Al Azmi et al. (2012) studied patients' attitudes toward service quality and its effects on their satisfaction in physical therapy in KSA Hospitals. They surveyed the relationship between the five dimensions of service quality and the three dimensions of patient satisfaction in 3 hospitals in the Saudi Arabia. On any dimension of the service quality, there was a positive and statistically significant effect on the patient satisfaction. Assurance maintained the most effective and empathy kept the least effect on patient satisfaction. The differences between this study and previous published studies are: the extension of two tools for measuring patient satisfaction and service quality in healthcare area by using Exploratory Factor Analysis (EFA) and then Conformity Factor Analysis (CFA). In addition, we used SEM to test the hypothesis. This method has many advantages toward 
other statistical methods for analyzing: synthesizing latent variables with observed variables, considering measurement and structural errors in structural models.

\section{Methodology}

In this section, we describe research model, hypotheses, and the population, methods to get the sample size, the research instrument, reliability and validity of the scale used.

\subsection{Research model}

In order to measure hospital service quality by five dimensions including tangibles, reliability, responsiveness, assurance, and empathy and its effects on patient satisfaction by three dimensions (general satisfaction, trust, and acceptance), the following model proposed as shown in Fig.1.

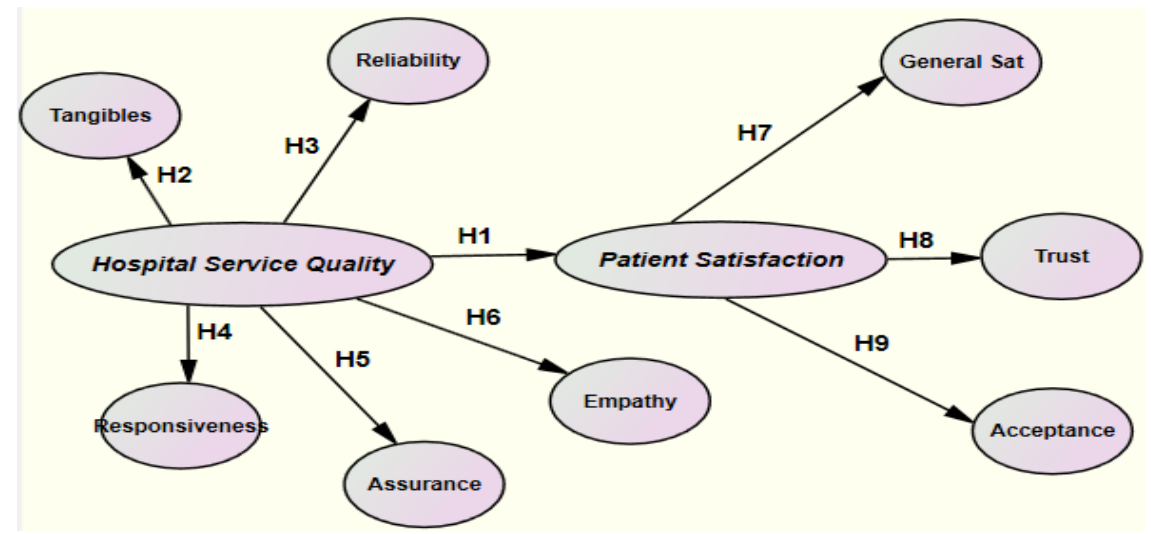

Fig.1. The research model

\subsection{Research hypotheses}

$\mathrm{H}_{1}$ : There is a positive and significant impact of hospital service quality dimensions on patient satisfaction.

$\mathrm{H}_{2}$ : There is a positive and significant impact of hospital service quality on tangibles.

$\mathrm{H}_{3}$ : There is a positive and significant impact of hospital service quality on reliability.

$\mathrm{H}_{4}$ : There is a positive and significant impact of hospital service quality on responsiveness.

$\mathrm{H}_{5}$ : There is a positive and significant impact of hospital service quality on assurance.

$\mathrm{H}_{6}$ : There is a positive and significant impact of hospital service quality on empathy.

$\mathrm{H}_{7}$ : There is a positive and significant impact of patient satisfaction on general satisfaction.

$\mathrm{H}_{8}$ : There is a positive and significant impact of patient satisfaction on trust.

$\mathrm{H}_{9}$ : There is a positive and significant impact of patient satisfaction on acceptance.

\subsection{The Population and methods to get the sample size}

The population of this study includes inpatients to the surgery, internal or post CCU departments in Shaheed Rajaei Cardiovascular Medical and Research Center. The statistical sample included the number of inpatients who experienced at least one night hospitalization at one of the mentioned departments of hospital in the summer of 2012. In this article, three methods were implemented to determine the sample size. The first, sampling without replacement from an unlimited population, because the number of inpatients are approximately definite but the number of their attendants are not exactly definite. To calculate the sample size, the following formula was used:

$\mathrm{n}=\frac{Z_{\propto / 2}^{2} \delta^{2}}{\varepsilon^{2}}$ 
where $n$ is the number of sample size, $Z_{\frac{\alpha}{2}}=1.96$ because error is $5 \% . \varepsilon$ is the error term and also, is considered 0.1 and $\delta$ is calculated from:

$\delta \approx \frac{\max \left(\mathrm{x}_{\mathrm{i}}\right)-\min \left(\mathrm{x}_{\mathrm{i}}\right)}{6}=\frac{5-1}{6}=0.667$

Consequently the minimum number of sample size is:

$\mathrm{n}=\frac{(1.96)^{2} *(.667)^{2}}{(0.1)^{2}} \cong 171$

In the second method, the sample size was determined by using "Morgan" and "Cohen" table. By considering the population of 300 patients hospitalized in surgery, internal and Post CCU departments, a required sample size would be 169 patients. In the third method, the sample size considered between $5 \mathrm{q}$ and $15 \mathrm{q}$ where $\mathrm{q}$ is the number of observed variables (questions). In this study, the number of observed variables is 31, 22 variables for service quality and 9 variables for patient satisfaction. Consequently, sample size would be between 155 and 465. Overall, 250 questionnaires have been distributed and 190 answered questionnaires were collected. The response rate was 76 percent.

\subsection{The research instruments}

In this study, two questionnaires were used: First, the scale proposed by (Parasuraman et al.,1991) was selected to measure service quality. This instrument includes 5 dimensions: Tangibles (4 Questions), Reliability (5 Questions), Responsiveness (4 Questions), Assurance (4 Questions), and Empathy (5 Questions). Second, patient satisfaction was measured by nine-item scale that developed by Maloles (1997) (Castro et al., 2004). For substantiation of this, exploratory factor analysis (EFA) and conformity factor analysis (CFA) were applied. Furthermore, patient satisfaction questionnaire with 9 scales after using EFA was included 3 dimensions: General Satisfaction (3 Questions), Trust (3 Questions), and Acceptance (3 Questions). Respondents stated their agreement with each questions through the use of a five-point Likert scale ranging from very low (1) to very high (5).

\subsection{Reliability and validity of the scale used}

The most common measure of reliability is internal-consistency reliability that measured with Cronbach Alpha. In this study, as the results have been indicated in Table 1, Cronbach Alpha of the tangibles was 0.779, Reliability was 0.889, Responsiveness was 0.800, Assurance was 0.743, and Empathy was 0.859. In addition, Cronbach Alpha for three dimensions of patient satisfaction questionnaire was calculated. Cronbach Alpha of the General Satisfaction was 0.729, Trust was 0.750, and Acceptance was 0.711.All of them were more than 0.7, indicate that the questionnaires are reliable. For testing the construct validity of the questionnaires, Exploratory Factor Analysis (EFA) and then Conformity Factor Analysis (CFA) were applied.

The results of expletory factor analysis have been shown in Table 1 for each dimension of Hospital service quality and Patient satisfaction. All 5 dimensions of Hospital service quality maintained in their initial structure and furthermore, 3 dimensions for patient satisfaction were identified. KMO in all of the dimensions was high and the sampling adequacy was confirmed. Factor loading $\%$ of variance in all of the dimensions was more than 0.5 that confirmed the remaining of factors in the model. The result of the expletory factor analysis (EFA) has been explored in section 4-3Measurement models results. 


\section{Table 1}

Results of expletory factor analysis

\begin{tabular}{llll}
\hline Questionnaire & KMO & Factor loading \% of variance & Cronbach Alpha \\
\hline Hospital service quality & 0.934 & 69.16 & 0.948 \\
tangibles & 0.761 & 60.22 & 0.779 \\
Reliability & 0.869 & 69.41 & 0.889 \\
Responsiveness & 0.780 & 62.54 & 0.800 \\
Assurance & 0.636 & 56.41 & 0.743 \\
Empathy & 0.849 & 64.15 & 0.859 \\
Patient satisfaction & 0.906 & 63.97 & 0.884 \\
General Satisfaction & 0.750 & 65.06 & 0.729 \\
Trust & 0.777 & 66.70 & 0.750 \\
Acceptance & 0.740 & 62.65 & 0.711 \\
\hline
\end{tabular}

\section{Data analysis and results}

We have used descriptive statistics to describe the sample characteristics and the gap analysis of the hospital service quality and the patient satisfaction questionnaires. In addition, structural equation modeling (SEM) was implemented to examine the proposed model by using analysis of moment structures (AMOS) software. We applied two-step approach to estimate a measurement model predecessor to the structural model as Anderson and Gerbing (1988) followed (Anderson \& Gerbing, 1988). In this section, we present the results of two measurement models analysis, structural model analysis and hypothesis testing.

\subsection{Sample Characteristics}

Table 2 shows sample characteristics. The Educational level of $80(42 \%)$ of sample respondents were Less than diploma, 60 (32\%) were diploma, 21 (11\%) were technician, $20(10 \%)$ were bachelor, and $9(5 \%)$ were Master and above.The Length of hospitalization of $18(9 \%)$ of sample members were one night, $52(27 \%)$ were 2 or 3 night, $62(33 \%)$ were 4 to 7 night, and $58(31 \%)$ were 8 night and above.

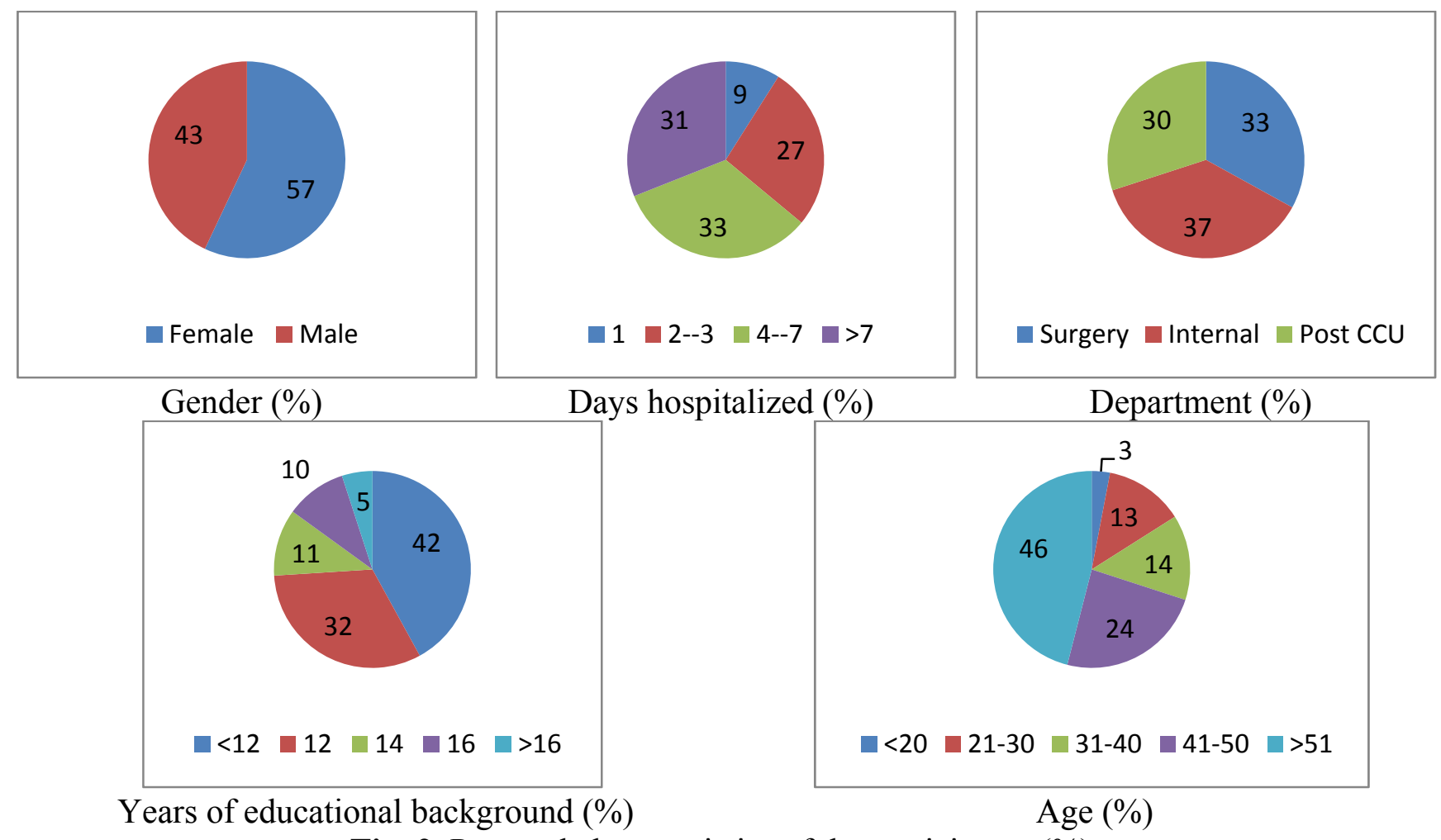

Fig. 2. Personal characteristics of the participants (\%) 


\subsection{Gap analysis of the hospital service quality and the patient satisfaction questionnaires}

According to Table 2, the maximum gap observed in responsiveness with the mean of gap was 1.0092 and the minimum gap observed in assurance with the mean of gap was -.4855. After responsiveness, maximum gap exist in empathy, and reliability. The hospital condition in assurance and tangible was appropriate than others. Table 2 shows the results of the Gap Analysis of Hospital service quality Dimensions. Patients had the most satisfaction in the question of "Well-dressed and neat employees and physicians" with the average of gap -.3842 in Tangible, but they had the least satisfaction in the question of "Calling the hospital employees when it is necessary" with the average of gap -1.0368 in Responsiveness.

\section{Table 2}

Gap Analysis of Hospital service quality Dimensions

\begin{tabular}{|c|c|c|c|c|}
\hline Questions & $\begin{array}{l}\text { Mean of } \\
\text { Perception } \\
\text { (P) }\end{array}$ & $\begin{array}{l}\text { Mean of } \\
\text { Expectation } \\
\text { (E) }\end{array}$ & $\begin{array}{l}\text { Mean of } \\
\text { Gap (P-E) }\end{array}$ & $\begin{array}{l}\text { Standard } \\
\text { Deviation } \\
\text { of Gap }\end{array}$ \\
\hline Tangible & 3.59 & 4.22 & -.62 & .653 \\
\hline Up-to-date equipment and facilities & 3.70 & 4.33 & -.63 & .784 \\
\hline Appealing physical environment and good signs, symbols and artifacts. & 3.25 & 4.06 & -.81 & 1.077 \\
\hline Well-dressed and neat employees and physicians & 3.96 & 4.34 & -.38 & .799 \\
\hline Appealing consumable elements used in cure and serve to patients & 3.48 & 4.14 & -.65 & .978 \\
\hline Reliability & 3.58 & 4.30 & -.71 & .666 \\
\hline Doing the promised service on time & 3.24 & 4.19 & -.95 & 1.035 \\
\hline Interesting to solve your problems & 3.32 & 4.20 & -.88 & 1.024 \\
\hline Doing everything right at the first time & 3.90 & 4.42 & -.52 & .865 \\
\hline Fulfilling the promised service at promised time & 3.46 & 4.24 & -.78 & .933 \\
\hline Keeping accurate records and documents & 4.01 & 4.45 & -.44 & .869 \\
\hline Responsiveness & 3.12 & 4.13 & -1.00 & .834 \\
\hline Calling the hospital employees when it is necessary & 3.16 & 4.20 & -1.03 & 1.218 \\
\hline Receiving prompt service from employees & 3.25 & 4.23 & -.98 & 1.126 \\
\hline Hospital employees are Willing to help & 3.04 & 4.05 & -1.01 & 1.182 \\
\hline Hospital employees have enough time to respond to my request promptly & 3.03 & 4.04 & -1.01 & 1.028 \\
\hline Assurance & 3.81 & 4.29 & -.48 & .660 \\
\hline Trustful of Hospital employees' behavior & 3.67 & 4.17 & -.50 & .952 \\
\hline Feel safe in transaction with Hospital employees & 3.82 & 4.29 & -.47 & .871 \\
\hline Hospital employees are polite & 3.90 & 4.37 & -.47 & .846 \\
\hline Hospital employees are knowledgeable enough to answer my questions & 3.85 & 4.35 & -.50 & .852 \\
\hline Empathy & 3.44 & 4.19 & -.75 & .661 \\
\hline Individual attention to patients & 3.28 & 4.19 & -.91 & 1.045 \\
\hline Have convenient hours in hospital department & 3.65 & 4.15 & -.50 & .827 \\
\hline Understanding the patients' specific needs & 3.38 & 4.21 & -.82 & .931 \\
\hline provide services in according to the interests of you & 3.35 & 4.15 & -.80 & .975 \\
\hline Pay attention to all patients equally irrespective of their social status & 3.52 & 4.26 & -.74 & 1.046 \\
\hline
\end{tabular}

Table 3

Analysis of patient satisfaction questionnaire

\begin{tabular}{lll}
\hline Questions & Mean & SD \\
\hline General Satisfaction & 3.68 & $\mathbf{. 9 2 2}$ \\
I am very satisfied with my hospital & 3.87 &. $\mathbf{8 6 0}$ \\
My hospital satisfy my needs & 3.99 &. .885 \\
My hospital is as good or better in comparison of the other hospitals & 3.19 & $\mathbf{1 . 0 2 1}$ \\
Trust & 3.83 & .958 \\
My complaints or problems are addressed in a fair manner & $\mathbf{4 . 1 1}$ & $\mathbf{. 8 9 6}$ \\
My hospital is very reliable & 3.84 & .926 \\
I like the people at my hospital & 3.55 & $\mathbf{1 . 0 5 2}$ \\
Acceptance & 3.53 & $\mathbf{1 . 0 1 1}$ \\
My hospital gives me the service I expect & 3.99 & .908 \\
My hospital provides excellent service & 2.82 & $\mathbf{1 . 2 0 4}$ \\
Overall, my experience with my hospital is positive & 3.80 & $\mathbf{. 9 2 1}$ \\
\hline
\end{tabular}

Table 3 shows the results of the analysis of the patient satisfaction questionnaire. Patients had the most satisfaction in the question of "My complaints or problems are addressed in a fair manner" with 
the average of 4.11 in Trust, but they had the least satisfaction in the question of "My hospital provides excellent service" with the average of 2.82 in Acceptance. Briefly, patients have the most satisfaction in trust with the mean of 3.83, then in General Satisfaction with the mean of 3.68 and they have the least satisfaction in Acceptance with the mean of 3.53.

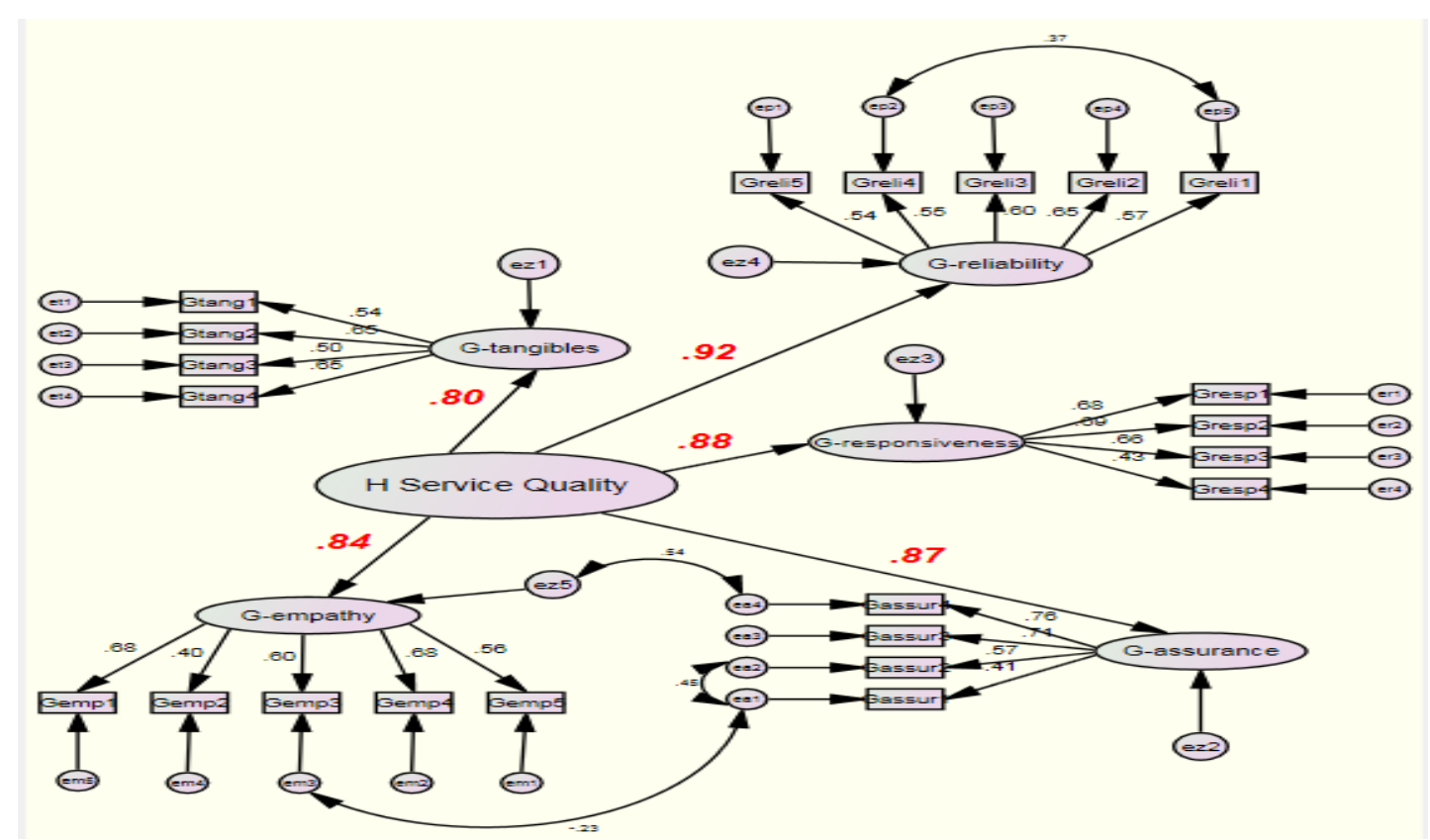

Fig. 3. The second-order conformity factor analysis (measurement model)

For hospital service quality

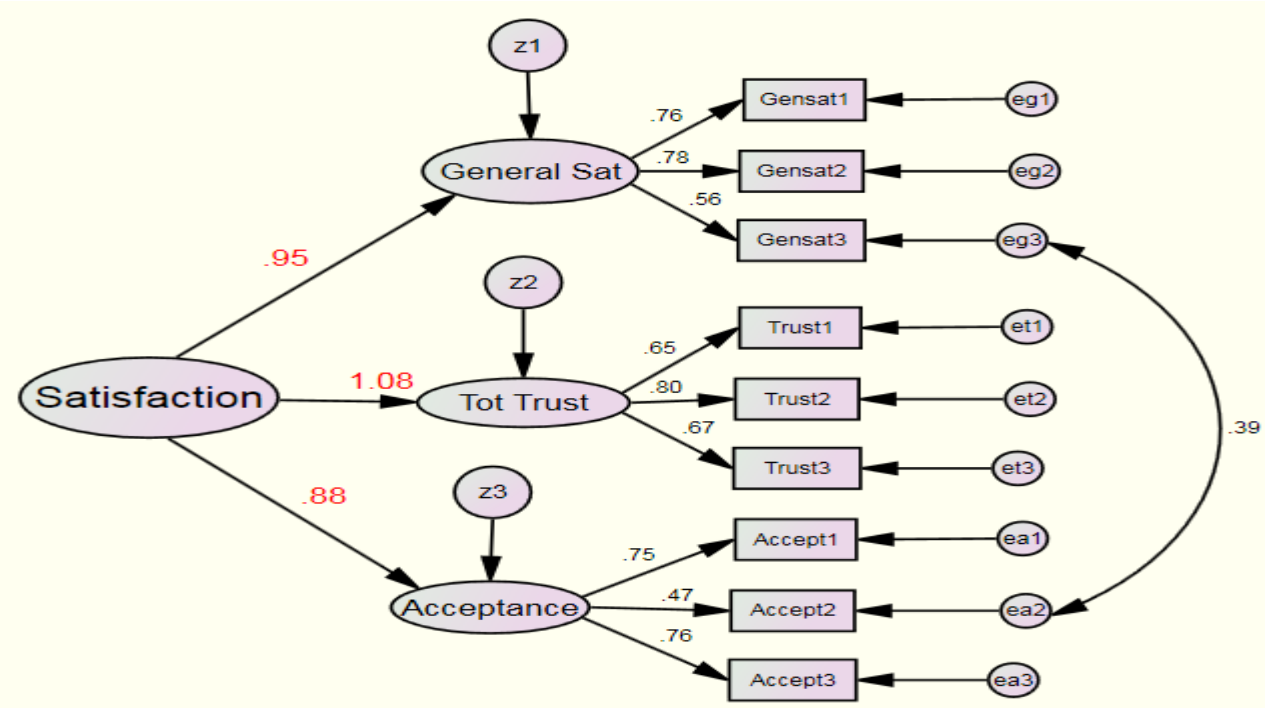

Fig. 4. The second-order conformity factor analysis (measurement model) For patient satisfaction

\subsection{Measurement models results}

We used the second-order conformity factor analysis as the type of the factor analysis that latent factors are influenced by another underlying latent variable. Fig. 3 shows the measurement model, the second-order conformity factor analysis for hospital service quality. 
Fig. 4 shows the measurement model, the second-order conformity factor analysis for patient satisfaction.

\subsection{Structural model results}

Fig. 5 shows the structural model between hospital service quality and patient satisfaction with standardized estimators.

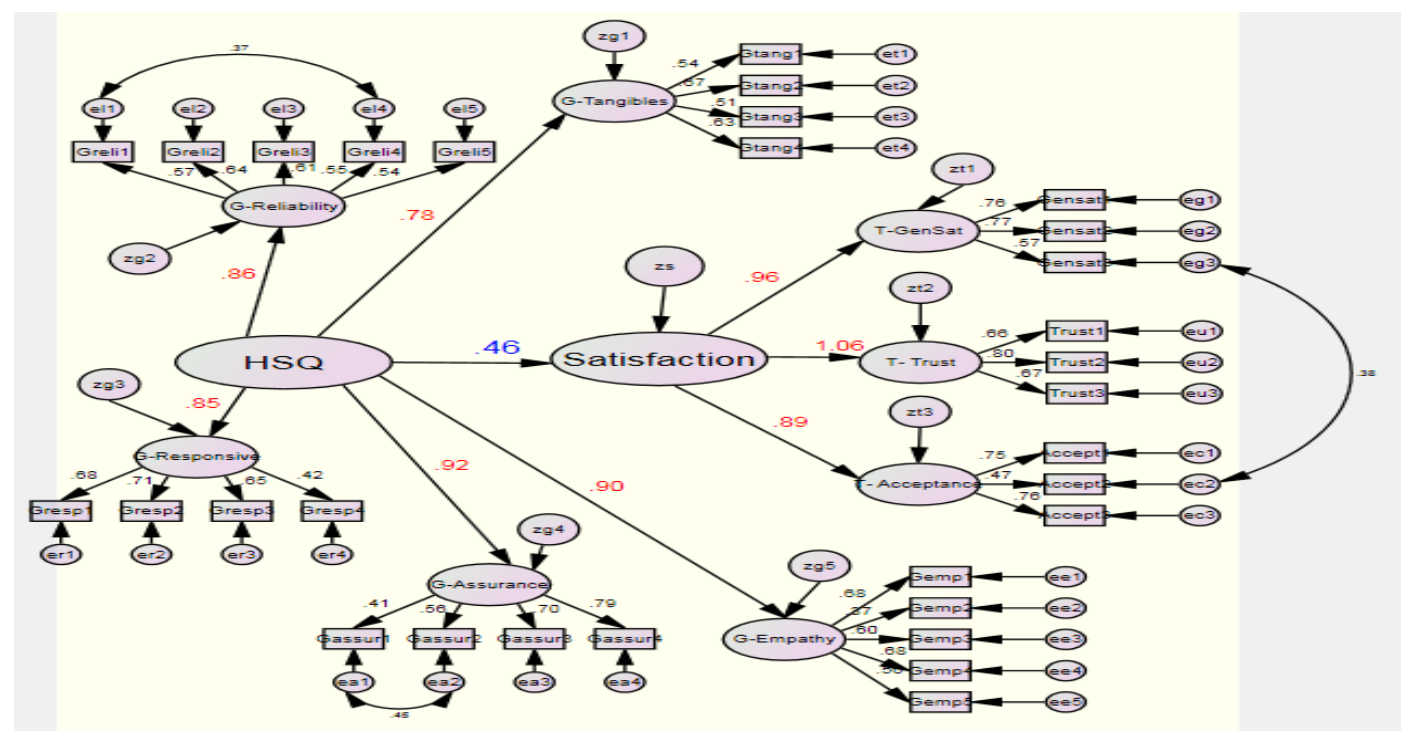

Fig. 5. The structural model and the standardized factor loading

Table 4 shows the results of the Goodness of fit measures for two measurement constructs (hospital service quality and patient satisfaction) and the structural model. Fit indices have been categorized in three groups: Absolute fit indices (i.e. CMIN, Chi-square /degrees of freedom, GFI, AGFI, RMSR), Comparative Fit indices (i.e. NNFI, NFI, CFI, IFI), and Parsimonious Fit indices (i.e. PRATIO, PNFI, PCFI, PGFI, RMSEA). All of the fit indices are more than criteria in measurement models and structure model. Consequently, proposed models are suitable.

Table 4

Goodness of fit indices for two measurement models and structural model

\begin{tabular}{|c|c|c|c|c|}
\hline \multirow[b]{2}{*}{ Goodness of fit measures } & \multicolumn{3}{|c|}{ Measurement models } & \multirow[b]{2}{*}{ Structural mode } \\
\hline & Criteria & $\begin{array}{c}\text { Hospital } \\
\text { Service quality }\end{array}$ & Patient satisfaction & \\
\hline \multicolumn{5}{|l|}{ Absolute fit indices } \\
\hline Distinct parameters & - & 53 & 22 & 74 \\
\hline Degrees of freedom (DF) & - & 200 & 23 & 422 \\
\hline Chi-square (CMIN) & - & 254.401 & 32.438 & 586.94 \\
\hline Chi-square /degrees of freedom & $\leq 3.0$ & 1.272 & 1.410 & 1.391 \\
\hline Goodness of fit index (GFI) & $\geq 0.90$ & 0.894 & 0.963 & 0.884 \\
\hline Adjusted goodness of fit index (AGFI) & $\geq 0.90$ & 0.865 & 0.927 & 0.855 \\
\hline Root mean square residual (RMSR) & $\leq 0.10$ & 0.05 & 0.041 & 0.061 \\
\hline \multicolumn{5}{|l|}{ Comparative Fit indices } \\
\hline Non-normed fit index (NNFI) & $\geq 0.90$ & 0.949 & 0.979 & 0.911 \\
\hline Normed fit index (NFI) & $\geq 0.90$ & 0.925 & 0.957 & 0.866 \\
\hline Comparative fit index (CFI) & $\geq 0.90$ & 0.956 & 0.987 & 0.919 \\
\hline $\begin{array}{l}\text { Incremental fit index (IFI) } \\
\text { Parsimonious Fit indices }\end{array}$ & $\geq 0.90$ & 0.957 & 0.987 & 0.921 \\
\hline Parsimony ratio (PRATIO) & - & 0.866 & 0.639 & 0.908 \\
\hline Parsimony adjustment to the NFI (PNFI) & $\geq 0.50$ & 0.714 & 0.611 & 0.696 \\
\hline Parsimony adjustment to the CFI (PCFI) & $\geq 0.50$ & 0.827 & 0.630 & 0.834 \\
\hline Parsimony goodness of fit index (PGFI) & $\geq 0.50$ & 0.706 & 0.592 & 0.710 \\
\hline Root mean square error of approximation (RMSEA) & $\leq 0.05$ & 0.038 & 0.047 & 0.045 \\
\hline
\end{tabular}


Table 5

Analysis of hypothesis

\begin{tabular}{|c|c|c|c|c|c|c|}
\hline Hypothesized Path & Hypothesis & $\begin{array}{l}\text { The estimation of } \\
\text { standardized } \\
\text { regression weight } \\
\text { (factor loadings) }\end{array}$ & $\begin{array}{l}\text { The estimation of } \\
\text { unstandardized } \\
\text { regression weight } \\
\text { (factor loadings) }\end{array}$ & $\begin{array}{l}\text { Standard } \\
\text { error } \\
\text { (S.E.) }\end{array}$ & $\begin{array}{l}\text { t-value } \\
\text { (C.R.) }\end{array}$ & P-value \\
\hline Hospital service quality $\rightarrow$ Patient satisfaction & H1 & 0.463 & 0.572 & 0.127 & 4.516 & $* * *$ \\
\hline Hospital service quality $\rightarrow$ Tangible & $\mathrm{H} 2$ & 0.784 & 0.660 & 0.135 & 4.904 & $* * *$ \\
\hline Hospital service quality $\rightarrow$ Reliability & H3 & 0.858 & 1.000 & Fixed & Fixed & \\
\hline Hospital service quality $\rightarrow$ Responsiveness & $\mathrm{H} 4$ & 0.848 & 0.729 & 0.167 & 4.360 & $* * *$ \\
\hline Hospital service quality $\rightarrow$ Assurance & H5 & 0.921 & 1.237 & 0.192 & 6.455 & $* * *$ \\
\hline Hospital service quality $\rightarrow$ Empathy & H6 & 0.898 & 1.266 & 0.213 & 5.942 & $* * *$ \\
\hline Patient satisfaction $\rightarrow$ General satisfaction & H7 & 0.958 & 1.000 & Fixed & Fixed & \\
\hline Patient satisfaction $\rightarrow$ Trust & $\mathrm{H} 8$ & 1.056 & 0.999 & 0.117 & 8.543 & $* * *$ \\
\hline Patient satisfaction $\rightarrow$ Acceptance & H9 & 0.891 & 0.975 & 0.110 & 8.847 & $* * *$ \\
\hline
\end{tabular}

\subsection{Testing the hypothesis}

The results of the second column in Table 5 show that there is a positive and significant impact of hospital service quality on patient satisfaction (0.463). Furthermore, there is a positive and significant impact of hospital service quality on tangible $(0.784)$, reliability $(0.858)$, responsiveness $(0.848)$, Assurance (0.921), and empathy (0.898). Furthermore, there is a positive and significant impact of Patient satisfaction on general satisfaction (0.958), trust (1), and acceptance (0.891). In column 5 in table, $\mathrm{t}$-values have calculated by dividing the estimation of unstandardized regression weight (column 3) to its standard error (column 4). All of the t-values are higher than 1.96 and all of the Pvalues are less than $0.05(* * *$ means that $\mathrm{P}<0.001)$, which indicate that loading factors have statistically meaningful difference with zero. Therefore, all of the nine hypotheses are accepted in this study.

\section{Conclusion, management strategies and future study}

Service Quality is to create value in studied hospital and password to achieve customer satisfaction. So hospitals to achieve distinction, should pay attention to patient's perceptions of service quality and put it in the priority of their activities, because the good quality of services impacts on customer satisfaction, profitability, Productivity, market share and reduces costs. By surveying hospital service quality questionnaire, the maximum gap observed in responsiveness with the mean of gap was 1.0092 and the minimum gap observed in assurance with the mean of gap was -.4855.After responsiveness, maximum gap exists in empathy, and reliability. The hospital condition in assurance and tangible were appropriate than others. Patients were dissatisfied in responsiveness, because Hospital employees were not willing to help, they didn't have enough time to respond to patient's request promptly, and they didn't call with patients when it was necessary. It is suggested that hospital managers pay more attention to human resource issues. Employees by increasing interpersonal skills devote more time to meet patients' requirements. By surveying patient satisfaction questionnaire, Patients had the most satisfaction in trust with the mean of 3.83 , then in General Satisfaction with the mean of 3.68 and they had the least satisfaction in Acceptance with the mean of 3.53. In this study, we have extended an instrument to measure the patient satisfaction with three dimensions extracted from exploratory factor analysis (EFA) by Principle component analysis method and conformity factor analysis (CFA). The result confirmed the proposed models.

In this study two measurement models were drown for measuring hospital service quality and patient satisfaction and one structural model that showed the relationship between them. The result of this study showed that there is a positive and significant impact of hospital service quality on patient satisfaction (0.463). In addition, other hypothesis was tested and there was a positive and significant relationship between hospital service quality and five dimensions. Furthermore, there was a positive and significant relationship between patient satisfaction and three dimensions (General Satisfaction, Trust, and Acceptance). 


\section{Management strategies:}

1- Implementing programs and training courses to promote the knowledge and individual/ interpersonal skills of employees, Flexibility and willingness to emphasize the nature of the service among employees in order to meet customer needs, equity, non-discrimination, citizenship and respectful behavior among employees that result in the patient's satisfaction and loyalty.

2- Identifying customer needs through periodic and continuous measurement of expectations and perception customer by SERVQUAL.

3- Utilizing appropriate information systems and applying scheduling can help to increase the responsiveness time among employees.

4- Implementing of Total Quality Management (TQM) in hospitals and investigation of the relationship between service quality and satisfaction Quality Management in Medical Centers to improve customer satisfaction and meet customer requirements.

\section{Future studies:}

1- This study was performed in one center. We recommend performing this study in multicenters in order to compare and rank the different treatment centers by using multi criteria decision making methods to determine the ranking of centers.

2- Provide solutions to lessen the gap between the perceptions and expectations of patients using the optimization models. For example, the objective function is defined: minimize the gap between perceptions and expectations.

3- Using fuzzy scale instead of interval scale like Likert, because respondents had more choice in filling the questionnaires.

4- Using ordinal variables such as patient education in structural equation modeling.

5- Combining the model used in this study with data envelopment analysis (DEA) methods, fuzzy SERVQUAL, multi-objective decision making (MODM) or multi-attribute decision making (MADM) techniques such as ANP or TOPSIS.

\section{Acknowledgments}

The authors gratefully acknowledge the assistance of department staff in Shaheed Rajaei Cardiovascular Medical and Research Center, especially Dr. Maziar Gholampour Dehaki, in the collection of data for this study.

\section{References}

Al Azmi, N., Al-Lozi, M., Zu'bi, M., \& Dahiyat, S. E. (2012). Patients Attitudes toward Service Quality and its Impact on their Satisfaction in Physical Therapy in KSA Hospitals. European Journal of Social Sciences, 34(2), 300-314.

Andaleeb, S. S. (2001). Service quality perceptions and patient satisfaction: a study of hospitals in a developing country. Social science \& medicine, 52(9), 1359-1370.

Anderson, J. C., \& Gerbing, D. W. (1988). Structural equation modeling in practice: A review and recommended two-step approach. Psychological bulletin, 103(3), 411-423.

Bolton, R. N., \& Drew, J. H. (1991). A longitudinal analysis of the impact of service changes on customer attitudes. The Journal of Marketing, 1-9.

Boshoff, C., \& Gray, B. (2004). The relationships between service quality, customer satisfaction and buying intentions in the private hospital industry. South African Journal of Business Management, 35(4), 27-37.

Boudreaux, E. D., \& O'Hea, E. L. (2004). Patient satisfaction in the emergency department: a review of the literature and implications for practice. Journal of emergency medicine, 26(1), 13-26. 
Castro, C. B., Armario, E. M., \& Ruiz, D. M. (2004). The influence of employee organizational citizenship behavior on customer loyalty. International journal of Service industry management, 15(1), 27-53.

Choi, K. S., Lee, H., Kim, C., \& Lee, S. (2005). The service quality dimensions and patient satisfaction relationships in South Korea: comparisons across gender, age and types of service. Journal of Services Marketing, 19(3), 140-149.

Cronin Jr, J. J., \& Taylor, S. A. (1992). Measuring service quality: a reexamination and extension. The Journal of Marketing, 55-68.

Owusu-Frimpong, N., Nwankwo, S., \& Dason, B. (2010). Measuring service quality and patient satisfaction with access to public and private healthcare delivery. International Journal of Public Sector Management, 23(3), 203-220.

Padma, P., Rajendran, C., \& Lokachari, P. S. (2010). Service quality and its impact on customer satisfaction in Indian hospitals: Perspectives of patients and their attendants. Benchmarking: An International Journal, 17(6), 807-841.

Pakdil, F., \& Harwood, T. N. (2005). Patient satisfaction in a preoperative assessment clinic: an analysis using SERVQUAL dimensions. Total Quality Management \& Business Excellence, 16(1), 15-30.

Parasuraman, A., Berry, L. L., \& Zeithaml, V. A. (1991). Refinement and reassessment of the SERVQUAL scale. Journal of retailing.

Parasuraman, A., Zeithaml, V. A., \& Berry, L. L. (1988). SERVQUAL: A Multiple-Item Scale for Measuring Consumer Perceptions of Service Quality. Journal of retailing, 64(1), 12-40.

Potter, C., Morgan, P., \& Thompson, A. (1994). Continuous Quality Improvement in an Acute Hospital:: A Report of an Action Research Project in Three Hospital Departments. International Journal of Health Care Quality Assurance, 7(1), 4-29.

Ramsaran-Fowdar, R. R. (2008). The relative importance of service dimensions in a healthcare setting. International Journal of Health Care Quality Assurance, 21(1), 104-124.

Spreng, R. A., \& Mackoy, R. D. (1996). An empirical examination of a model of perceived service quality and satisfaction. Journal of retailing, 72(2), 201-214.

Tabish, S. A. (1998). Towards development of professional management in Indian hospitals. Journal of Management in Medicine, 12(2), 109-119.

Tucker, J. L., \& Adams, S. R. (2001). Incorporating patients' assessments of satisfaction and quality: an integrative model of patients' evaluations of their care. Managing Service Quality, 11(4), 272287.

Zeithaml, V. A. (2000). Service quality, profitability, and the economic worth of customers: what we know and what we need to learn. Journal of the Academy of Marketing Science, 28(1), 67-85. 